\title{
ASSESSING CERTIFIED MANURE ANALYSIS LABORATORY ACCURACY AND VARIABILITY
}

\author{
J. R. Sanford, R. A. Larson, M. F. Digman
}

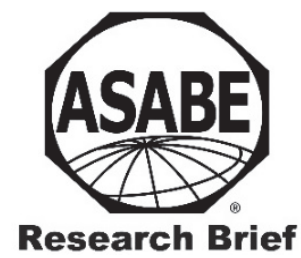

\section{HighLIGHTS}

- Manure analysis proficiency laboratories were assessed for accuracy and precision.

- Total nitrogen analysis was accurate and precise and is a strength of industry.

- Ammonium analysis resulted in most variability in laboratory results.

- Phosphorus and potassium mean comparison indicated significant differences between lab results.

ABSTRACT. Nutrient management planning (NMP) is an effective method for ensuring proper nutrient applications to agricultural fields. At livestock facilities, quantifying manure nutrient content is crucial for producers to obtain accurate and precise data to properly apply nutrients to the field to optimize crop yields while minimizing nutrient losses to the environment. In this study, eight manure analysis proficiency program (MAP) certified laboratories each received six replicates of four manure samples (two dairy and two swine) and analyzed for total solids (TS), total nitrogen (TN), ammoniacal nitrogen $\left(\mathrm{NH}_{4}-\mathrm{N}\right)$, phosphate $\left(\mathrm{P}_{2} \mathrm{O}_{5}\right)$, and potash $\left(\mathrm{K}_{2} \mathrm{O}\right)$. Laboratories were compared using the MAP robust statistics comparison approach and a one-way ANOVA using laboratory means. Total nitrogen analysis had high precision and accuracy across laboratories selected for analysis. However, laboratories had less accuracy and precision in determining $\mathrm{NH}_{4}-\mathrm{N}$ concentrations. Additionally, while $\mathrm{P}_{2} \mathrm{O}_{5}$ and $\mathrm{K}_{2} \mathrm{O}$ met MAP standards for accuracy and precision, there was concerns for reading accuracy, as the median absolute deviation (MAD) to overall median ratio was high (ranging from $5.9 \%$ to $14.4 \%$ ) and many of the laboratory means were statistically different.

Keywords. Laboratory variability, Manure, Nutrient analysis.

$\mathrm{M}$ anure is rich in essential elements required for plant growth, including nitrogen $(\mathrm{N})$, phosphorus $(\mathrm{P})$, and potassium $(\mathrm{K})$, and is often land applied as a fertilizer. While application of manure to cropland is an effective way to restore organic matter and nutrients to the soil (Risse et al., 2006), over application contributes to environmental issues such as surface or groundwater contamination from excess nutrients (Burkholder et al., 2007; Kleinman, 2017). To apply nutrients at recommended agronomic rates, nutrient management plans (NMPs) have been established in the United States to guide fertilizer application rates (USDA-NRCS, 2015). A NMP is used to guide assessments of soil nutrients to determine the required fertilizer application needed to obtain

This work is licensed under a Creative Commons Attribution-NonCommercial-NoDerivatives 4.0 International License https://creative commons.org/licenses/by-nc-nd/4.0/

Submitted for review in July 2020 as manuscript number NRES 14214; approved for publication as a Research Brief by the Natural Resources \& Environmental Systems Community of ASABE in October 2020.

The authors are Joseph R. Sanford, Assistant Professor, Soil and Crop Science, University of Wisconsin-Platteville, Platteville, Wisconsin; Rebecca A. Larson, Associate Professor, and Matthew F. Digman, Assistant Professor, Biological Systems Engineering, University of Wisconsin-Madison, Madison, Wisconsin. Corresponding author: Joseph R. Sanford, 1 University Plaza, Platteville, WI 53818; phone: 608-3421459; email: sanfordj@uwplatt.edu. optimal crop yields (Beegle et al., 2000). Additionally, NMPs have the benefit of mitigating environmental impacts associated with over application of nutrients (Amon-Armah et al., 2013). Consequently, there is a global push for widespread adoption (Mueller et al., 2012; Pasuquin et al., 2014; Xu et al., 2016). In the United States, many individual states have developed regulations and set guidelines for NMPs (USDA-NRCS, 2015).

When NMPs are developed for cropland using synthetic fertilizer, development of application rates is relatively straight forward as plant nutrient requirements can be met with a variety of fertilizer products which can be blended at different concentrations. However, manure does not have fixed nutrient characteristics requiring greater system management. Depending on regulations, producers may be able to use manure nutrient concentrations based on historical manure data (Lorimor et al., 2004; USDA-NRCS, 2008). However, manure characteristics between farms can be highly variable (Jokela et al., 2010), thus the best practice is to sample and analyze manure before land application for site specific manure application rates (Aguirre-Villegas et al., 2018).

For operations using manure fertilizer, developing an effective NMP is highly dependent on multiple factors including the manure analytical procedures. Methods have been standardized in the United States for conducting manure 
analysis to improve laboratory predictions (Peters et al., 2003). A certification process known as the Manure Analysis Proficiency (MAP) program has been established to improve the precision, accuracy, and accountability in analysis (Floren et al., 2006). The MAP program certifies laboratories by using a robust statistical analysis and scoring system. Each year, participating laboratories analyze a set of homogenized manure samples from the Minnesota Department of Agriculture and results are compared with other laboratories in the industry. A scoring system is used to rank laboratories in terms of accuracy and precision. When labs are flagged for poor accuracy or precision performance, they are deducted three or five points, respectively. Labs are then ranked, and at least the top $80 \%$ of eligible labs will pass for endorsement (Floren et al., 2006). In North America, 47 laboratories are certified under the MAP program (MNDA, 2020). The goal of the study was to conduct an external review of the MAP program to assess its effectiveness at ensuring manure analysis laboratories are providing precise and accurate nutrient characteristics prediction needed for NMP.

\section{METHODS}

\section{LABORATORIES}

Eight laboratories were randomly selected from the Minnesota Department of Agriculture's MAP certified laboratories (MNDA, 2020). To maintain anonymity, letter identifiers have been assigned to each lab. Each laboratory analyzed six replicates of four manure samples (two dairy and two swine) for total solids (TS), total N (TN), ammoniacal nitrogen $\left(\mathrm{NH}_{4}-\mathrm{N}\right), \mathrm{P}$ as phosphate $\left(\mathrm{P}_{2} \mathrm{O}_{5}\right)$, and $\mathrm{K}$ as potash $\left(\mathrm{K}_{2} \mathrm{O}\right)$. Analysis methodologies used by each laboratory are listed in table 1. All laboratory reports were reviewed for units, significant figures, analysis personnel identification, specified methods, and detection limits. Additionally, any signs of reporting errors were noted when analyzing the data. Clerical errors were first analyzed for by assessing if lab results were off by a specific factor to other data within that specific lab and other labs. If data was off by a factor of 10 it was assumed results were reported to the incorrect decimal place. Next if labs that reported data on more than one unit (i.e., \% and lb 1000 gal $^{-1}$ ), values were checked using conversion factors to see if data was converted correctly. If clerical errors were assumed in a lab report, the data was corrected for analysis purposes. Simplified versions of laboratory reports are presented in the supplemental material (tables S1-S8). All laboratory data was converted into $\mathrm{g} \mathrm{kg}^{-1}$ units for data analysis purposes.

\section{Manure Samples}

Manures were collected from the University of Wisconsin Arlington Research Station. Two $150 \mathrm{~L}$ samples were taken from the dairy manure storage, denoted as dairy A (DA) and dairy B (DB), and two from the swine manure storage denoted as swine A (SA) and swine B (SB), for a total of four samples. During subsampling, a submersible pump was used to homogenize the sample and $500 \mathrm{~mL}$ subsamples were pulled continuously and labeled with sequential numerical values. Samples were then frozen and prepared for shipment to analytical laboratories for analysis.

Laboratories received six subsamples from each manure composite sample. Three of the samples were sequential and three were randomly selected to assess any homogenization issues during sampling. If sample draw bias were observed the three sequential samples would be used for estimating intra-laboratory analysis, and the three random samples would be used for inter-laboratory analysis. However, there was no observation of a sample draw bias for any of the samples or parameters (fig. S1-S5), thus all six samples were used as replicates.

\section{Data AnAlysis}

Data analysis was conducted in SAS (SAS, 2013) using procedures outlined in the MAP program (Floren et al., 2006). Intra-laboratory precision was determined using the mean, standard deviation, and coefficient of variation (CV) for the replicate subsamples. Laboratory $\mathrm{CV}$ is designated as the repeatability statistic ( $\mathrm{Rp})$ and the overall median $\mathrm{CV}$ of laboratories was designated as the reproducibility statistic (Rd). Laboratories with $\mathrm{Rp}$ that was greater than three times the Rd were flagged for poor precision. Laboratory accuracy was determined using median rather than the mean to reduce the effect from outliers as manure laboratory data is typically not normally distributed (Floren et al., 2006). In this method, the data were analyzed for median and median absolute deviation (MAD). Laboratory accuracy was assessed based on

Table 1. Laboratory analytical methods.

\begin{tabular}{|c|c|c|c|c|c|c|c|c|c|c|}
\hline \multirow{3}{*}{$\begin{array}{c}\mathrm{Lab} \\
\mathrm{A}\end{array}$} & \multicolumn{2}{|c|}{ TS } & \multicolumn{2}{|c|}{$\mathrm{TN}$} & \multicolumn{2}{|c|}{$\mathrm{NH}_{4}-\mathrm{N}$} & \multicolumn{2}{|c|}{$\mathrm{P}_{2} \mathrm{O}_{5}$} & \multicolumn{2}{|c|}{$\mathrm{K}_{2} \mathrm{O}$} \\
\hline & Drying & TMECC & & AOAC & Distillation & AOAC & $\mathrm{ICP}$ & $\mathrm{AOAC}$ & $\mathrm{ICP}$ & AOAC \\
\hline & $\left(70^{\circ} \mathrm{C}\right)$ & 03.09 & TKN & 2001.11 & Titration & 973.49 & (Dry Ash) & 985.01 & (Dry Ash) & 985.02 \\
\hline \multirow{2}{*}{$\mathrm{E}$} & Drying & TMECC & \multirow[b]{2}{*}{ TKN } & $\mathrm{AOAC}$ & Colorimetry & USEPA & ICP & EPA & ICP & EPA \\
\hline & $\left(50^{\circ} \mathrm{C}\right)$ & 03.09 & & 2001.11 & auto Analyzer & 351.2 & (Digestion) & 3050 & (Digestion) & 3050 \\
\hline \multirow{2}{*}{$\mathrm{F}$} & Drying & TMECC & \multirow{2}{*}{ Combustion } & AOAC & Distillation & AOAC & ICP & $\mathrm{AOAC}$ & ICP & AOAC \\
\hline & $\left(110^{\circ} \mathrm{C}\right)$ & $03.03-\mathrm{A}$ & & 990.03 & Titration & 973.49 & (Digestion) & 985.01 & (Digestion) & 985.01 \\
\hline \multirow{2}{*}{$\mathrm{H}$} & Drying & TMECC & \multirow{2}{*}{ TKN } & AOAC & Distillation & $\mathrm{AOAC}$ & ICP & $\mathrm{AOAC}$ & ICP & AOAC \\
\hline & $\left(105^{\circ} \mathrm{C}\right)$ & $03.03-\mathrm{A}$ & & 2001.11 & Titration & 973.49 & (Dry Ash) & 985.01 & (Dry Ash) & 985.01 \\
\hline \multirow{2}{*}{$\mathrm{J}$} & Drying & TMECC & \multirow{2}{*}{ TKN } & AOAC & Distillation & AOAC & ICP & $\mathrm{AOAC}$ & ICP & AOAC \\
\hline & $\left(80^{\circ} \mathrm{C}\right)$ & 03.09 & & 2001.11 & Titration & 973.49 & (Dry Ash) & 985.01 & (Dry Ash) & 985.01 \\
\hline \multirow{2}{*}{$\mathrm{K}$} & Drying & TMECC & \multirow{2}{*}{ Combustion } & AOAC & Distillation & AOAC & $\mathrm{ICP}$ & EPA & ICP & EPA \\
\hline & $\left(105^{\circ} \mathrm{C}\right)$ & 03.03-A & & 990.3 & Titration & 973.49 & (Digestion) & 3050 & (Digestion) & 3050 \\
\hline \multirow{2}{*}{$\mathrm{L}$} & Drying & TMECC & \multirow{2}{*}{ Combustion } & AOAC & Colorimetry & USEPA & ICP & EPA & ICP & EPA \\
\hline & $\left(100^{\circ} \mathrm{C}\right)$ & $03.03-\mathrm{A}$ & & 990.03 & auto Analyzer & 351.2 & (Digestion) & $3051 \mathrm{~A}$ & (Digestion) & $3051 \mathrm{~A}$ \\
\hline \multirow{2}{*}{ M } & Drying & TMECC & \multirow{2}{*}{ Combustion } & AOAC & Colorimetry & USEPA & ICP & EPA & ICP & EPA \\
\hline & $\left(105^{\circ} \mathrm{C}\right)$ & $03.03-\mathrm{A}$ & & 990.03 & auto Analyzer & 351.2 & (Digestion) & $3051 \mathrm{~A}$ & (Digestion) & $3051 \mathrm{~A}$ \\
\hline
\end{tabular}


a confidence interval of laboratory median greater than or less than 2.5 times the MAD. Laboratories with median values outside of the confidence limit were flagged for accuracy. Labs that were flagged for accuracy and precision were deducted three and/or five points, respectively. With four samples analyzed there was a possible of 32 total points for each parameter.

Data was also analyzed using laboratory mean data. Data was assessed for robustness using randomization/presumption testing (proc multtest) in SAS to validate assumption that the lab assignment was independent of the outcome. Laboratory means were assessed for significant difference using one-way analysis of variance (ANOVA) t-test and Tukey HSD test $(\mathrm{p}=0.05)$.

\section{RESULTS AND DISCUSSION}

\section{MANURE REPORTING}

Laboratories reported $\mathrm{TN}, \mathrm{P}_{2} \mathrm{O}_{5}$, and $\mathrm{K}_{2} \mathrm{O}$ in $\mathrm{lb} 1000$ gal $^{-1}$, but some reported additional units such as $\mathrm{ppm}, \mathrm{lb}^{-1}$ or weight percentage (table S9). Since all manures in this study were classified as liquid or slurry manure, reporting in $\mathrm{lb}$ $1000 \mathrm{gal}^{-1}$ is recommended (Peters et al., 2003). None of the laboratory reports presented the density used to convert analytical data into lb $1000 \mathrm{gal}^{-1}$. Calculations or follow up correspondence with the lab were used to determine that six labs reported using the recommended conversion factor of the density of water $\left(0.997 \mathrm{~g} \mathrm{~mL}^{-1}\right.$ or $\left.8.33 \mathrm{lb} \mathrm{gal}^{-1}\right)$ (Peters et al., 2003). Lab H used $1.011 \mathrm{~g} \mathrm{~mL}^{-1}$ (or $8.44 \mathrm{lb} \mathrm{gal}^{-1}$ ), and lab M measured the density of each manure sample. The significant figures used in reporting were consistent across laboratories, with all labs reporting two decimal places.

Clerical errors were also noted in some of the laboratory results. Lab $\mathrm{J}$ appeared to have reporting issues with $\mathrm{P}_{2} \mathrm{O}_{5}$ and $\mathrm{K}_{2} \mathrm{O}$. Consequently, 8 of the 24 samples analyzed were off by a factor of 10 . Additionally, lab $\mathrm{K}$ reported $\mathrm{NH}_{4}-\mathrm{N}$ in lb $1000 \mathrm{gal}^{-1}$, but when compared to the percentage values reported, it was apparent that data had been stated as $\mathrm{lb}^{\mathrm{b}} \mathrm{ton}^{-1}$. These clerical errors were corrected for data analysis in this study. However, it is important to note that these errors may not be caught by the typical user, which could result in under or over application of manure nutrients, resulting in potential yield or environmental impacts.

\section{Total Solids ANAlysis}

For dairy A (DA), dairy B (DB), swine A (SA), and swine $\mathrm{B}$ (SB), the total solids (TS) median absolute deviations (MAD) were $2.7 \%, 3.1 \%, 3.4 \%$, and $5.6 \%$ of the overall medians, and the reproducibility statistics (Rd) were $1.8 \%$, $2.6 \%, 1.8 \%$, and $3.5 \%$, respectively (table A1). The MAD to median ratio and $\mathrm{Rd}$ values were lower than reported in past studies (Floren et al., 2006), which may indicate an improvement in precision and accuracy for manure analysis labs. Using the MAP scoring systems, three of the laboratories received perfect scores (table A2). In general laboratory median values were accurate for dairy and swine samples (fig. 1). However, Rp values were higher for swine samples, and there was evidence that laboratories had precision issues with the low solids swine samples (SB) (fig. S6). Lab L
(A) 5.0

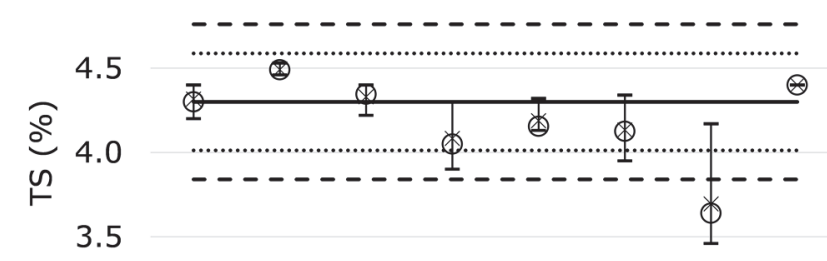

3.0

(B) 6.5

$A^{a b c} \quad E^{a} \quad F^{a b c} \quad H^{d} \quad J^{b d c} K^{d c} \quad L^{e} \quad M^{a b}$

$6.0 \quad------------------$

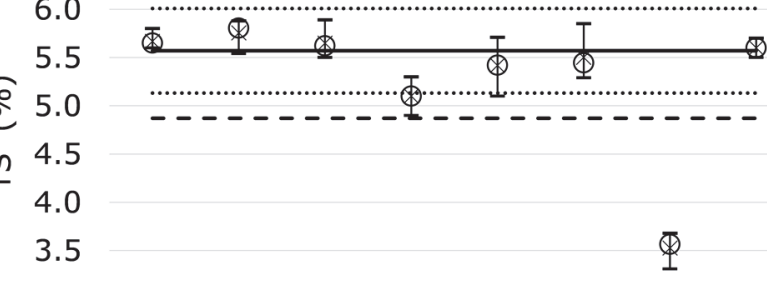

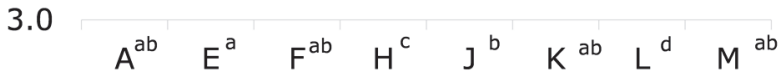

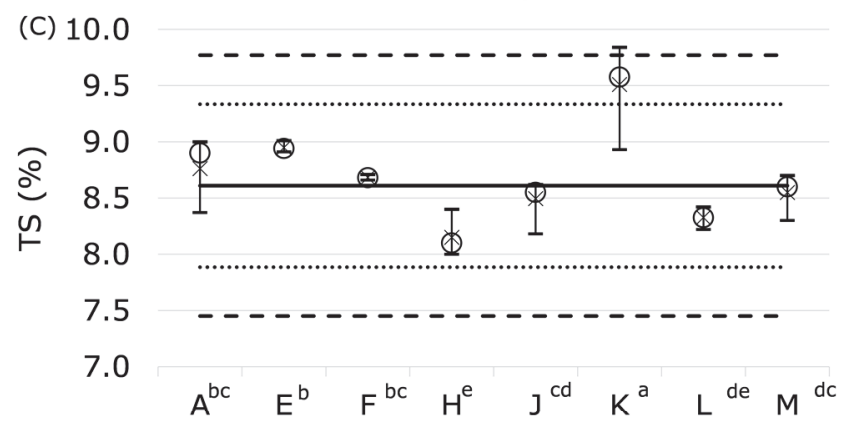

(D) 2.0

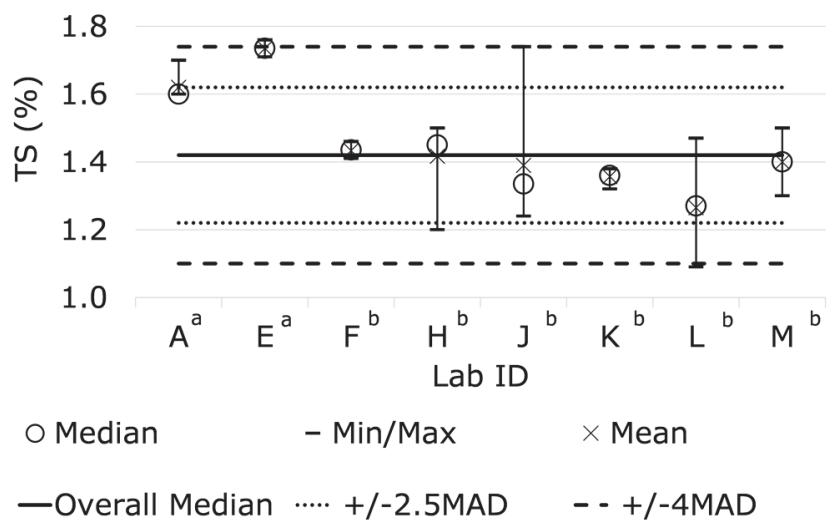

Figure 1. TS laboratory data (including median, mean, minimum, and maximum) and overall median and MAD confidence intervals of \pm 2.5 and \pm 4 for (A) Dairy A, (B) Dairy B, (C) Swine A, and (D) Swine B. On the $x$-axis, different superscripts indicate significant difference $(p=0.05)$ in laboratory means.

received only $50 \%$ of the points (table A2), due to issues in accuracy and precision across all subsamples. For both dairy samples, the laboratory median was flagged for accuracy and mean was significantly lower $(\mathrm{p}=0.05)$ than other laboratories (fig. 1). Additionally, lab L had precision issues on two of the samples, DA and SB (fig. S6). 
While the typical user may not use TS content for application purposes, ensuring accurate and precise TS measurement is vital for providing additional parameter data. When providing data on a wet or dry basis, is it imperative that TS content be accurate to ensure accuracy of other parameters. The manure analysis procedures allow for TS to be conducted at $50^{\circ} \mathrm{C}, 70^{\circ} \mathrm{C}$, or $110^{\circ} \mathrm{C}$ (Peters et al., 2003). Three labs used temperatures below $100^{\circ} \mathrm{C}$ for drying (labs $\mathrm{A}, \mathrm{E}$, and $\mathrm{J}$ ), while the rest used greater than $100^{\circ} \mathrm{C}$ drying temperature. Labs A and E median TS were typically higher than the overall median, which may be indicative of residual moisture in the sample due to insufficient drying at the lower temperature. Each lab was flagged once for high TS content, suggesting it may be important to standardized to $110^{\circ} \mathrm{C}$ TS methodology in the industry.

\section{Total Nitrogen ANALYSIS}

For DA, DB, SA, and SB, TN MADs were $4.4 \%, 4.5 \%$, $3.3 \%$, and $5.4 \%$ of the overall medians, and Rds were $2.8 \%$, $2.0 \%, 2.1 \%$, and $2.6 \%$, respectively (table A1). These accuracy and precision ranges are similar to values reported in a past assessment (Floren et al., 2006). Generally, laboratory TN were accurate and precise (fig. 2 and fig. S7). Six of the eight laboratories received perfect scores indicating interand intra-laboratory consistency (table A2). However, one lab certified for TN analysis under the MAP program had significant issues. Lab K received an accuracy flag for every manure sample, and precision flags for two, resulting in 19\% of MAP point allowance.

There are two approved methods for TN manure analysis including total Kjeldahl $\mathrm{N}$ (TKN) digestion and $\mathrm{N}$ by combustion. Half the labs used TKN and the other half N combustion (table 1). All the TKN labs received perfect scores and two out of four combustion labs did as well. Floren et al. (2006) suggested combustion N analysis compared to TKN may be more accurate and precise based on their assessment of 55 labs. However, that was not observed in this study, but this study had a relatively small sample population of labs for both analysis methods.

\section{AmmoniaCal Nitrogen ANALYSIS}

For DA, DB, SA, and SB the $\mathrm{NH}_{4}-\mathrm{N}$ MADs were $7.4 \%$, $8.6 \%, 9.2 \%$, and $3.7 \%$ of the overall medians, and Rds were $2.0 \%, 3.9 \%, 4.4 \%$, and $2.6 \%$, respectively (table A1). Floren et al. (2006) also reported high MAD to overall median ratios, suggesting that $\mathrm{NH}_{4}-\mathrm{N}$ analysis remains a weakness of the manure analysis industry for providing accurate results. In this study three labs received multiple accuracy (fig. 3) and precision (fig. S8) flags, resulting in obtaining less than $30 \%$ of the possible MAP points, while the other five labs received perfect scores (table A2). Lab E, L, and M all had median values that were less than 2.5 times MAD from the overall median for all manure samples (fig. 3).

Laboratory analysis method had a significant impact on $\mathrm{NH}_{4}-\mathrm{N}$ results. The three labs that received low scores used the colorimetric spectrometer methodology, while the other five labs used the distillation and titration method. Floren et al. (2006) observed a similar trend between labs using colorimetric method compared to electrode or distillation methods. The significant difference between the two methods
(A) 3.0

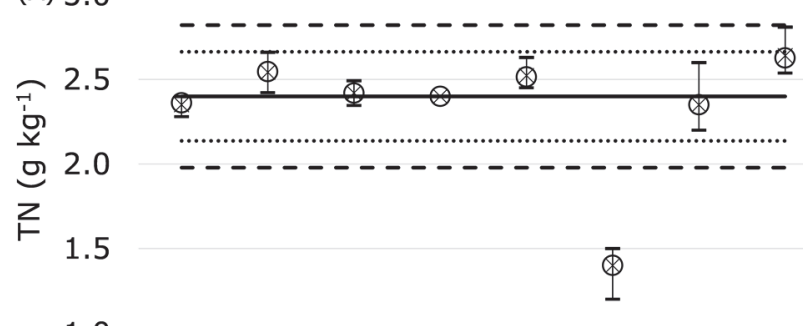

1.0

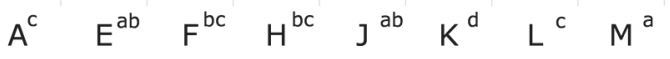

(B) 3.0

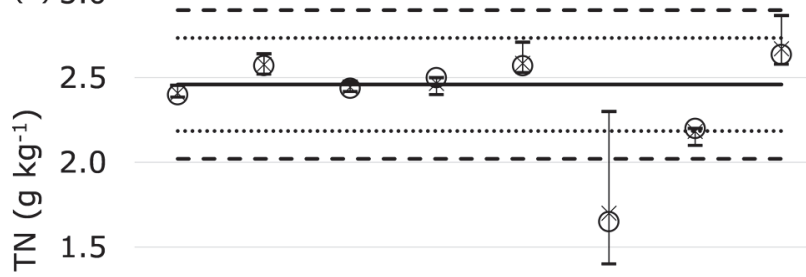

1.0

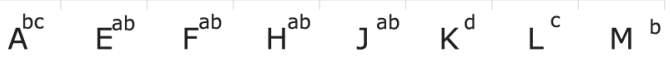

(C) 7.0

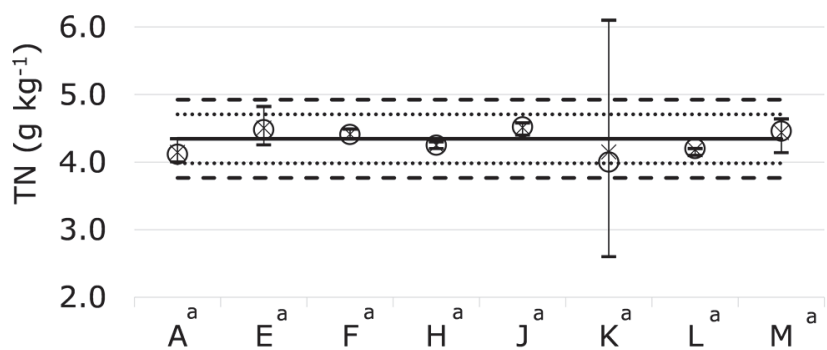

(D) 12.0

10.0

F 8.0

문. 6.0

乙 4.0

2.0

0.0

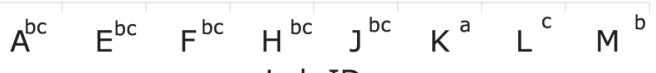

Lab ID

$\begin{array}{lll}\text { OMedian } & - \text { Min/Max } & \times \text { Mean } \\ \text {-Overall Median } & \cdots . .++/-2.5 \text { MAD } & --+/-4 \text { MAD }\end{array}$

Figure 2. TN laboratory data (including median, mean, minimum, and maximum) and overall median and MAD confidence intervals of \pm 2.5 and \pm 4 for (A) Dairy A, (B) Dairy B, (C) Swine A, and (D) Swine B. On the $x$-axis, different superscripts indicate significant difference $(p=0.05)$ in laboratory means.

indicates that this may be an issue in the manure analysis testing industry. It should be noted that none of the laboratories in this study were MAP certified for $\mathrm{NH}_{4}-\mathrm{N}$ analysis and, in fact, out of the 45 laboratories currently listed as certified MAP labs only two are certified for $\mathrm{NH}_{4} \mathrm{~N}$ testing (MNDA, 2020). 
(A) 1.5

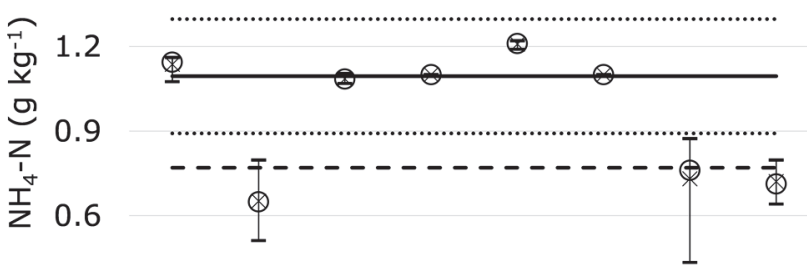

0.3

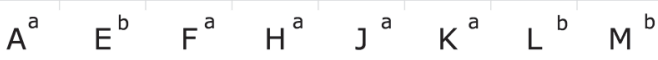

(B) 1.6

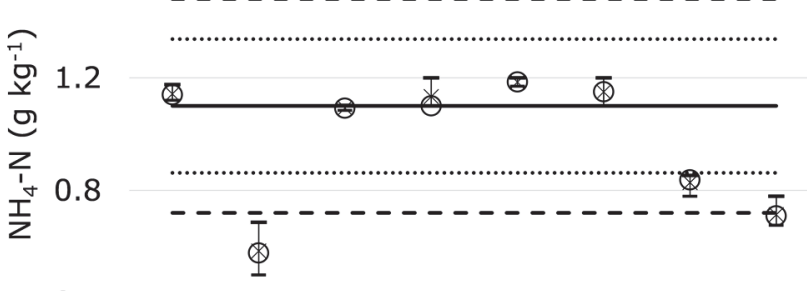

0.4

$A^{a b} \quad E^{e} \quad F^{b} \quad H^{a b} \quad J^{a} \quad K^{a b} \quad L^{c} \quad M^{d}$

(C) 1.9

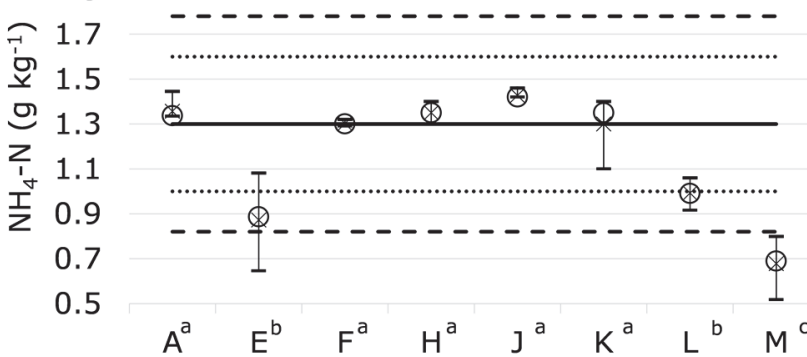

(D)

2.0

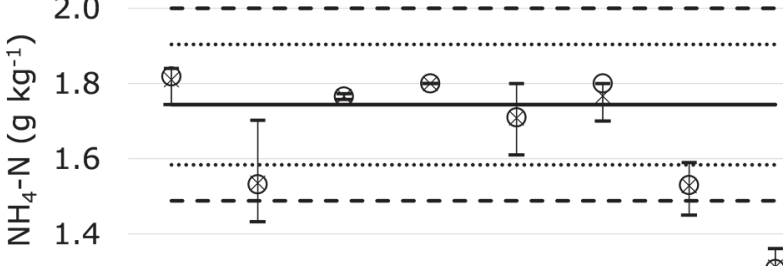

1.2

$$
\begin{aligned}
& A^{a} \quad E^{b} \quad F^{a} \quad H^{a} \quad J^{a} \quad K^{a} \quad L^{b} \quad M^{c} \\
& \text { Lab ID } \\
& \text { O Median } \quad \text { - Min/Max } \quad \times \text { Mean } \\
& \text {-Overall Median … +/-2.5MAD } \quad--+/-4 \text { MAD }
\end{aligned}
$$

Figure 3. $\mathrm{NH}_{4}-\mathrm{N}$ laboratory data (including median, mean, minimum, and maximum) and overall median and MAD confidence intervals of \pm 2.5 and \pm 4 for (A) Dairy A, (B) Dairy B, (C) Swine A, and (D) Swine $\bar{B}$. On the $x$-axis, different superscripts indicate significant difference $(p=0.05)$ in laboratory means.

\section{Phosphorus ANALYSIS}

For DA, DB, SA, and SB the $\mathrm{P}_{2} \mathrm{O}_{5}$ MADs were 5.9\%, $7.6 \%, 14.4 \%$, and $8.8 \%$ of the overall medians, and Rds were $2.7 \%, 3.3 \%, 4.4 \%$, and $3.6 \%$, respectively (table A1). Floren et al. (2006) reported a similar range of MAD to median ratio of $7.4 \%$ to $18 \%$ and $\mathrm{Rd}$ of $2.2 \%$ to $4.2 \%$ when comparing 66
(A) 1.3

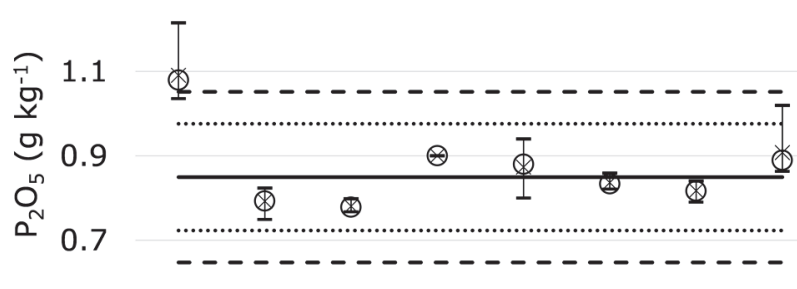

(B) 1.5

$$
A^{a} \quad E^{e} \quad F^{e} \quad H^{b c} \quad{ }^{b d c} K^{c d e} L^{d e} M^{b}
$$

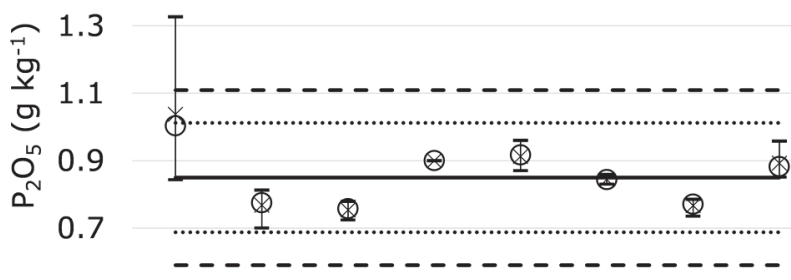

0.5

(C) 15.0

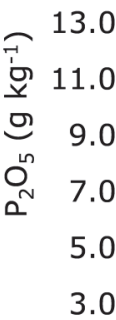

$A^{a} \quad E^{c} \quad F^{c} \quad H^{b} \quad J^{b} \quad K^{b c} \quad L^{c} \quad M^{b}$

(D) 1.6

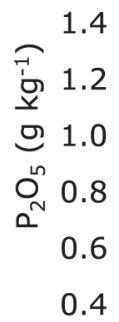

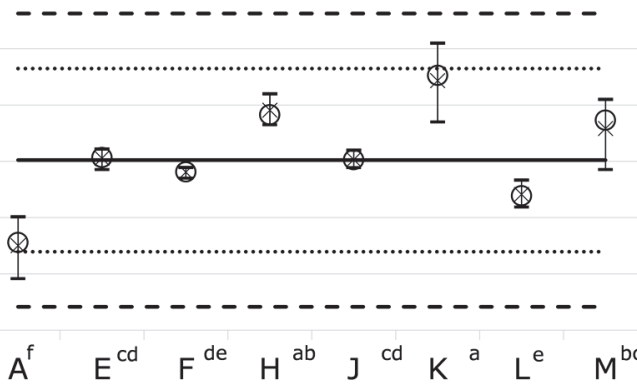

0.4
$A^{a} \quad E^{b c} \quad F^{a b c} \quad H^{a} \quad J^{a} \quad K^{c d} \quad L^{d} \quad M^{a b}$ Lab ID

$\begin{array}{lll}\text { O Median } & - \text { Min/Max } & \times \text { Mean } \\ \text {-Overall Median } & \cdots . .+ \text { + } & \\ \end{array}$

Figure 4. $\mathrm{P}_{2} \mathrm{O}_{5}$ laboratory data (including median, mean, minimum, and maximum) and overall median and MAD confidence intervals of \pm 2.5 and \pm 4 for (A) Dairy A, (B) Dairy B, (C) Swine A, and (D) Swine $\bar{B}$. On the $x$-axis, different superscripts indicate significant difference $(p=0.05)$ in laboratory means.

different laboratories. Five of the laboratories in this study did not receive any flags using the MAP method, resulting in perfect scores (table A2). Three labs received flags (fig. 4 and fig. S9), but all received over $65 \%$ of the possible points. While the MAP analysis method leads to the laboratories obtaining satisfactory results, it is important to note that the MAD to median ratio was high relative to the other 
compositional factors observed. This may indicate that the industry struggles to provide accurate predictions of $\mathrm{P}_{2} \mathrm{O}_{5}$. Comparing the laboratory means, there was notably more significant differences $(\mathrm{p}=0.05)$ detected between laboratories for $\mathrm{P}_{2} \mathrm{O}_{5}$ (fig. 4) compared to results from TN (fig. 1). Laboratories being able to provide accurate $\mathrm{P}_{2} \mathrm{O}_{5}$ manure prediction is necessary to make management decisions that affect manure application rates and the resulting soil $\mathrm{P}$ concentrations. In aquatic environments, $\mathrm{P}$ is often the limiting nutrient for toxic algae blooms, and small amounts of P lost to surface waters can result in eutrophic water quality issues (Daniel et al., 1998; Dils and Heathwaite, 1999; Kleinman, 2017). Additionally, in livestock operations manure application rates are often restricted based on P content of manure. Historical data demonstrates that soil receiving livestock manure often have high soil P concentrations (Kleinman, 2017). Thus, when applying based on $P$, it is essential that accurate and precise results are provided to ensure NMPs do not result in overapplication, and this should be an area that the manure testing industry focuses on improving.

Two methods are outlined in the recommended analysis for manure include ICP analysis using dry ash or acid digestion (Peters et al., 2003). Three labs reported using the dry ash method, while the other five used acid digestion ICP analysis (table 1). However, there was no evidence that the method for $\mathrm{P}_{2} \mathrm{O}_{5}$ analysis impacted on the accuracy or precision.

\section{Potassium AnAlysis}

For DA, DB, SA, and SB the $\mathrm{K}_{2} \mathrm{O}$ MADs were 3.7\%, $4.7 \%, 9.0 \%$, and $2.9 \%$ of the overall medians, and Rds were $4.9 \%, 4.8 \%, 6.6 \%$, and $2.8 \%$, respectively (table A 1 ). Floren et al. (2006) reported MAD to median ratios ranged between $7.0 \%$ to $8.5 \%$ in 2006 , suggesting inter-laboratory improvement in $\mathrm{K}_{2} \mathrm{O}$ analysis. However, the $\mathrm{Rd}$ values in this study were higher than the $3.0 \%$ average previously reported. Four laboratories receiving perfect scores and all labs received at least $84 \%$ of possible points, suggesting that $\mathrm{K}_{2} \mathrm{O}$ analysis is a strength of the industry (table A2). However, similar issues as reported in $\mathrm{P}_{2} \mathrm{O}_{5}$ were observed, with some samples leading to a high MAD to overall median ratio. Using the laboratory means, there were notably more significant differences $(\mathrm{p}=0.05)$ detected between laboratories (fig. 5), similar to $\mathrm{P}_{2} \mathrm{O}_{5}$ observations. Additionally, the high $\mathrm{Rp}$ and $\mathrm{Rd}$ values indicate high intra-laboratory variability (fig. S10). This suggests there may still be difficulties in providing precise and accurate $\mathrm{K}_{2} \mathrm{O}$ values across the industry. None of the laboratories had received certification for $\mathrm{K}$ analysis, and in fact none of the certified MAP laboratories have $\mathrm{K}$ certification (MNDA, 2020). This is concerning as $\mathrm{K}$ is an essential nutrient for obtaining optimal crop yields. Currently the general manure laboratory certification, labs must meet MAP criteria for $\mathrm{N}$ and $\mathrm{P}$. However, since $\mathrm{K}$ is an important nutrient in evaluating additional crops fertilizer needs it may be beneficial to include $\mathrm{K}$ in the general criteria for certification to ensure all laboratories are meeting standards.
(A) 2.3

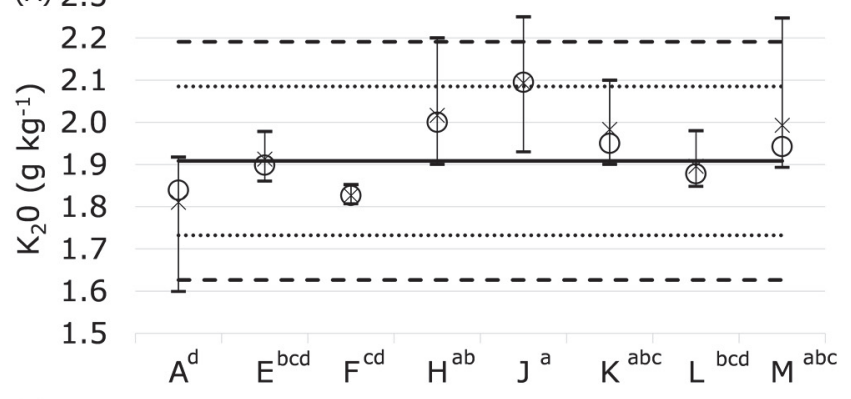

(B) 2.4

2.3

2.2

के 2.1

o 2.0

1.9

实 1.8

1.7

1.6

1.5

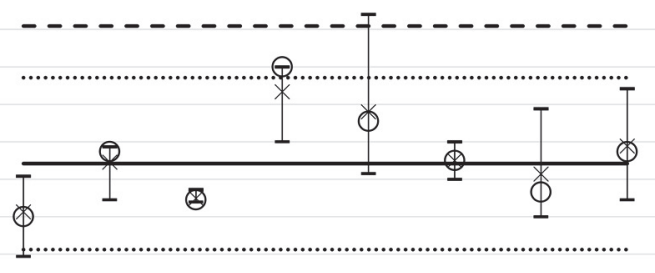

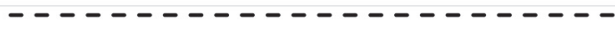

$A^{c} \quad E^{b c} \quad F^{c} \quad H^{a} \quad J^{a b} \quad K^{b c} \quad L^{b c} \quad M^{a b c}$

(C) 1.1

1.0

0.9

它 0.8

으 0.7

요 0.6

0.4

0.3

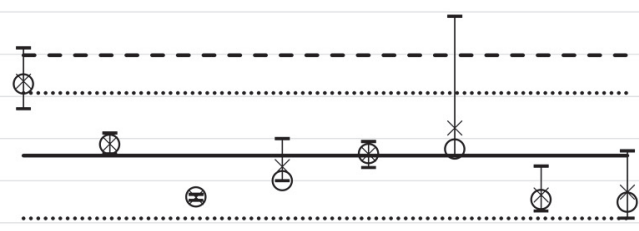

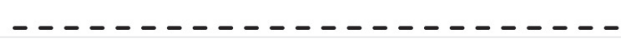

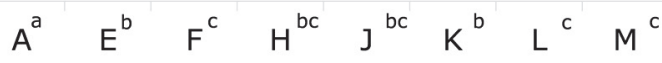

(D) 1.9

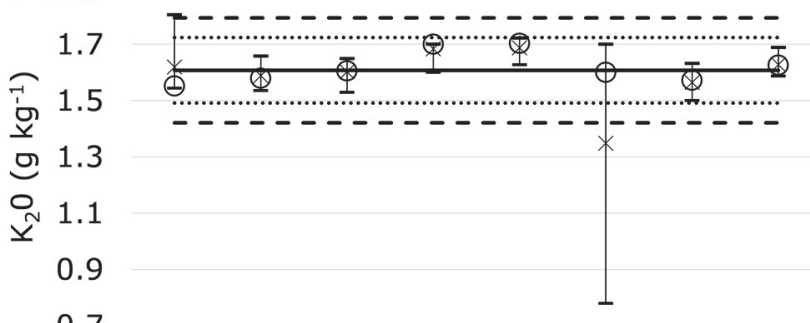

0.7

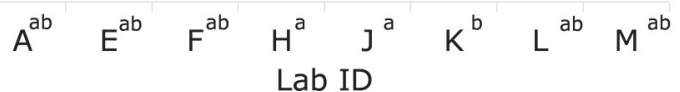

O Median $\quad-$ Min/Max $\quad \times$ Mean

-Overall Median $\cdots \cdot \cdot+/-2.5$ MAD $\quad-\cdot+/$-4MAD

Figure 5. $\mathrm{K}_{2} \mathrm{O}$ laboratory data (including median, mean, minimum, and maximum) and overall median and MAD confidence intervals of \pm 2.5 and \pm 4 for (A) Dairy A, (B) Dairy B, (C) Swine A, and (D) Swine B. On the $x$-axis, different superscripts indicate significant difference $(p=0.05)$ in laboratory means.

\section{Conclusion}

To ensure proper nutrient management from livestock facilities, it is crucial that manure analysis laboratories provide precise and accurate data for NMP purposes. In this study eight MAP certified laboratories were compared for TS, TN, $\mathrm{NH}_{4}-\mathrm{N}, \mathrm{P}_{2} \mathrm{O}_{5}$, and $\mathrm{K}_{2} \mathrm{O}$. Overall, $\mathrm{TN}$ appeared to be a 
strength of the industry as a majority of labs received high scores using MAP analysis and labs were generally similar in TN reporting. Poor performing measures were generally randomly scattered across laboratories (table A2), with the exception of lab L, which consistently had poor accuracy and precision. The $\mathrm{NH}_{4}-\mathrm{N}$ data suggested that the industry needs to improve, as there was significant difference between laboratories. Additionally, it was evident that methodology used for $\mathrm{NH}_{4}-\mathrm{N}$ analysis had a significant impact on the reported values. While $\mathrm{P}_{2} \mathrm{O}_{5}$ results appeared satisfactory using the MAP analysis method, there was still evidence that accuracy was an issue in the industry, as there was significant difference between many of the laboratory means. At livestock facilities $\mathrm{P}$ is often the restricting nutrient for application, consequently, it is crucial for accurate and precise laboratory results to ensure proper application rates. Additionally, $\mathrm{K}_{2} \mathrm{O}$ data was similar to $\mathrm{P}_{2} \mathrm{O}_{5}$ results, suggesting that it could also be improved.

\section{ACKNOWLEDGMENT}

This material is based upon work that is supported by John Deere GmbH \& Co. KG. (Straßburger Allee 3, Kaiserslautern, Germany) and the Wisconsin Dairy Innovation Hub. Any opinions, findings, conclusions, or recommendations expressed in this publication are those of the author(s) and do not necessarily reflect the views of the funders. The authors also appreciate project support from undergraduate research assistants Julia Rogers, Miriam Zarling, and Samantha Payne.

\section{SuPPlemental Material}

Supplemental material for this article may be found on figshare online at https://figshare.com/articles/journal_contribution/Assessing_Certified_Manure_Analysis_Laboratory_Accuracy_and_Variability_Supplemental_Material/12 665084

\section{REFERENCES}

Aguirre-Villegas, H. A., Sharara, M. A., \& Larson, R. A. (2018). Nutrient variability following dairy manure storage agitation. Appl. Eng. Agric., 34(6), 908-917. https://doi.org/10.13031/aea.12796

Amon-Armah, F., Yiridoe, E. K., Ahmad, N. H., Hebb, D., Jamieson, R., Burton, D., \& Madani, A. (2013). Effect of nutrient management planning on crop yield, nitrate leaching and sediment loading in thomas brook watershed. Environ. Manag., 52(5), 1177-1191. https://doi.org/10.1007/s00267-0130148-Z

Beegle, D. B., Carton, O. T., \& Bailey, J. S. (2000). Nutrient management planning: Justification, theory, practice. $J E Q$, 29(1), $72-79$. https://doi.org/10.2134/jeq2000.00472425002900010009x

Burkholder, J., Libra, B., Weyer, P., Heathcote, S., Kolpin, D., Thorne, P. S., \& Wichman, M. (2007). Impacts of waste from concentrated animal feeding operations on water quality. Environ. Health Perspectives, 115(2), 308-312. https://doi.org/10.1289/ehp.8839

Daniel, T. C., Sharpley, A. N., \& Lemunyon, J. L. (1998). Agricultural phosphorus and eutrophication: A symposium overview. JEQ, 27(2), 251-257. https://doi.org/10.2134/jeq1998.00472425002700020002x
Dils, R. M., \& Heathwaite, A. L. (1999). The controversial role of tile drainage in phosphorus export from agricultural land. Water Sci. Technol., 39(12), 55-61.

https://doi.org/10.2166/wst.1999.0529

Floren, J., Miller, R. O., \& Montgomery, B. (2006). Manure analysis manure analysis proficiency (MAP) program final report. December, Appendix A. Retrieved from http://www.mda.state.mn.us/licensing/licensetypes/mapprogram. aspx

Jokela, W. E., Tilley, J. P., \& Ross, D. S. (2010). Manure nutrient content on Vermont dairy farms: Long-term trends and relationships. Commun. Soil Sci. Plant Analysis, 41(5), 623-637. https://doi.org/10.1080/00103620903531193

Kleinman, P. J. A. (2017). The persistent environmental relevance of soil phosphorus sorption saturation. Current Pollution Reports, 3(2), 141-150. https://doi.org/10.1007/s40726-0170058-4

Lorimor, J., Powers, W., \& Sutton, A. (2004). Manure characteristics. In Manure management systems series (2nd ed.). Midwest Plan Service.

MNDA. (2020). Manure analysis proficiency (MAP) laboratories. Minnesota Department of Agriculture.

Mueller, N. D., Gerber, J. S., Johnston, M., Ray, D. K., Ramankutty, N., \& Foley, J. A. (2012). Closing yield gaps through nutrient and water management. Nature, 490(7419), 254-257. https://doi.org/10.1038/nature11420

Pasuquin, J. M., Pampolino, M. F., Witt, C., Dobermann, A., Oberthur, T., Fisher, M. J., \& Inubushi, K. (2014). Closing yield gaps in maize production in Southeast Asia through site-specific nutrient management. Field Crops Res., 156, 219-230. https://doi.org/10.1016/j.fcr.2013.11.016

Peters, J., Combs, S. M., Hoskins, B., Jarman, J., Kovar, J. L., Watson, M. E.,... Wolf, N. (2003). Recommended methods of manure analysis (A3769). University of Wisconsin- Ext.

Risse, L. M., Cabrera, M. L., Franzluebber, A. K., Gaskin, J. W., Gilley, J. E., Killorn, R.,... Zhang, H. (2006). Land application of manure for beneficial reuse. In J. M. Rice, D. F. Caldwell, \& F. J. Humenik (Eds.), Animal agriculture and the environment (pp. 283-316). National Center for Manure and Animal Waste Management White Papers.

SAS. (2013). Base SAS ${ }^{\circledR} 9.4$ Procedures guide: Statistical procedures. 2nd Ed. Cary, NC: SAS Institute Inc.

USDA-NRCS. (2008). Agricultural waste characteristics. In Agricultural waste management field handbook. Washington, DC: USDA-NRCS.

USDA-NRCS. (2015). Conservation Practice Code 590 - Nutrient management. Washington, DC: USDA-NRCS.

Xu, X., He, P., Pampolino, M. F., Li, Y., Liu, S., Xie, J.,... Zhou, W. (2016). Narrowing yield gaps and increasing nutrient use efficiencies using the Nutrient Expert system for maize in Northeast China. Field Crops Res., 194, 75-82. https://doi.org/10.1016/j.fcr.2016.05.005 


\section{APPENDIX}

Table A1. Dairy A, Dairy B, Swine A, and Swine B composite sample overall mean $(\overline{\mathbf{x}})$, overall median $(\tilde{\mathbf{x}})$, MAD, MAD to $X$ ratio and Rd for each parameter.

\begin{tabular}{|c|c|c|c|c|c|}
\hline & $\begin{array}{c}\overline{\mathrm{x}} \\
\left(\mathrm{g} \mathrm{kg}^{-1}\right) \\
\end{array}$ & $\begin{array}{c}\tilde{\mathrm{x}} \\
\left(\mathrm{g} \mathrm{kg}^{-1}\right) \\
\end{array}$ & $\begin{array}{c}\text { MAD } \\
\left(\mathrm{g} \mathrm{kg}^{-1}\right)\end{array}$ & $\begin{array}{c}\mathrm{MAD} / \tilde{\mathrm{x}} \\
(\%)\end{array}$ & $\mathrm{Rd}(\%)$ \\
\hline \multicolumn{6}{|l|}{ Dairy A } \\
\hline $\mathrm{TS}^{[\mathrm{a}]}$ & 4.20 & 4.30 & 0.12 & 2.7 & 1.79 \\
\hline $\mathrm{TN}$ & 2.33 & 2.40 & 0.11 & 4.4 & 2.80 \\
\hline $\mathrm{NH}_{4}-\mathrm{N}$ & 0.97 & 1.09 & 0.08 & 7.4 & 1.96 \\
\hline $\mathrm{P}_{2} \mathrm{O}_{5}$ & 0.87 & 0.85 & 0.05 & 5.9 & 2.67 \\
\hline $\mathrm{K}_{2} \mathrm{O}$ & 1.94 & 1.91 & 0.07 & 3.7 & 4.92 \\
\hline \multicolumn{6}{|l|}{ Dairy B } \\
\hline $\mathrm{TS}^{[\mathrm{a}]}$ & 5.28 & 5.57 & 0.18 & 3.1 & 2.57 \\
\hline $\mathrm{TN}$ & 2.38 & 2.46 & 0.11 & 4.5 & 1.98 \\
\hline $\mathrm{NH}_{4}-\mathrm{N}$ & 0.98 & 1.10 & 0.10 & 8.6 & 3.93 \\
\hline $\mathrm{P}_{2} \mathrm{O}_{5}$ & 0.86 & 0.85 & 0.06 & 7.6 & 3.34 \\
\hline $\mathrm{K}_{2} \mathrm{O}$ & 1.96 & 1.94 & 0.09 & 4.7 & 4.75 \\
\hline \multicolumn{6}{|l|}{ Swine A } \\
\hline $\mathrm{TS}^{[\mathrm{a}]}$ & 8.68 & 8.61 & 0.29 & 3.4 & 1.76 \\
\hline $\mathrm{TN}$ & 4.32 & 4.34 & 0.14 & 3.3 & 2.14 \\
\hline $\mathrm{NH}_{4}-\mathrm{N}$ & 1.16 & 1.30 & 0.12 & 9.2 & 4.44 \\
\hline $\mathrm{P}_{2} \mathrm{O}_{5}$ & 9.18 & 9.04 & 1.30 & 14.4 & 4.39 \\
\hline $\mathrm{K}_{2} \mathrm{O}$ & 0.66 & 0.66 & 0.06 & 9.0 & 6.57 \\
\hline \multicolumn{6}{|l|}{ Swine B } \\
\hline $\mathrm{TS}^{[\mathrm{a}]}$ & 1.53 & 1.42 & 0.08 & 5.6 & 3.49 \\
\hline $\mathrm{TN}$ & 3.35 & 2.40 & 0.13 & 5.4 & 2.63 \\
\hline $\mathrm{NH}_{4}-\mathrm{N}$ & 1.65 & 1.74 & 0.06 & 3.7 & 2.55 \\
\hline $\mathrm{P}_{2} \mathrm{O}_{5}$ & 0.98 & 1.03 & 0.09 & 8.8 & 3.60 \\
\hline $\mathrm{K}_{2} \mathrm{O}$ & 1.59 & 1.61 & 0.05 & 2.9 & 2.76 \\
\hline
\end{tabular}

[a] TS $\bar{x}, \tilde{x}$, and MAD data is in $\%$ rather than $\mathrm{g} \mathrm{kg}^{-1}$.
Table A2. Laboratory scores according to MAP program analysis. There are 32 possible points, and labs receive a three or five point deduction for precision and accuracy flags, respectively.

\begin{tabular}{cccccc}
\hline & \multicolumn{5}{c}{ Parameter Score } \\
\cline { 2 - 6 } $\mathrm{Lab}$ & $\mathrm{TS}$ & $\mathrm{TN}$ & $\mathrm{NH}_{4}-\mathrm{N}$ & $\mathrm{P}_{2} \mathrm{O}_{5}$ & $\mathrm{~K}_{2} \mathrm{O}$ \\
\hline $\mathrm{A}$ & 32 & 32 & 32 & 21 & 27 \\
$\mathrm{E}$ & 27 & 32 & 6 & 32 & 32 \\
$\mathrm{~F}$ & 32 & 32 & 32 & 32 & 32 \\
$\mathrm{H}$ & 27 & 32 & 32 & 32 & 27 \\
$\mathrm{~J}$ & 29 & 32 & 32 & 32 & 27 \\
$\mathrm{~K}$ & 27 & 6 & 32 & 29 & 29 \\
$\mathrm{~L}$ & 16 & 27 & 9 & 24 & 32 \\
$\mathrm{M}$ & 32 & 32 & 6 & 32 & 32 \\
\hline
\end{tabular}

